\title{
EFFECT OF LABETALOL AND ESMOLOL ON ONSET OF ACTION OF ROCURONIUM: A PROSPECTIVE DOUBLE-BLINDED RANDOMIZED CONTROLLED TRIAL
}

\author{
RANJITA ACHARYA, SHAKTI BEDANTA MISHRA, ARUN RATH, BHABANI SANKARA PATI*, KALYANI BALA NAYAK \\ Department of Anaesthesiology, Institute of Medical Sciences and SUM Hospital, Bhubaneswar, Odisha, India. Email: zulupati@gmail.com
}

Received: 05 January 2018, Revised and Accepted: 19 February 2018

ABSTRACT

Objective: Labetalol is a non-selective beta blocker which is used for the treatment of hypertension. Its role in controlling the hemodynamic response to tracheal intubation is established. This comparative controlled study was carried out to verify its effects on time to onset of action of rocuronium in comparison to esmolol.

Methods: We randomized patients into two groups. Group A receiving injection labetalol $0.25 \mathrm{mg} / \mathrm{kg}$ diluted to $10 \mathrm{ml}$ with $0.9 \%$ saline and Group B receiving $0.5 \mathrm{mg} / \mathrm{kg}$ of esmolol in $10 \mathrm{ml} 0.9 \%$ saline before surgery. The time to onset of action of rocuronium, systolic blood pressure, and heart rate were recorded. The adverse reactions were observed in the post-operative period.

Results: A total of 60 patients were randomized into two groups. At the time of intubation, the systolic blood pressure and heart rate were similar between the two groups. The onset of action of rocuronium was decreased significantly in the labetalol group.

Conclusion: Labetalol attenuates the hemodynamic response to tracheal intubation both during intubation. It also slightly decreases the time to onset of action of rocuronium.

Keywords: Rocuronium, Muscle relaxation, Labetalol.

(C) 2018 The Authors. Published by Innovare Academic Sciences Pvt Ltd. This is an open access article under the CC BY license (http://creativecommons. org/licenses/by/4. 0/) DOI: http://dx.doi.org/10.22159/ajpcr.2018.v11i6.23515

\section{INTRODUCTION}

Endotracheal intubation is the gold standard method for maintaining the airway during general anesthesia. Direct laryngoscopy and passage of a tracheal tube are noxious stimuli that can provoke adverse responses in cardiovascular, respiratory, and other physiological systems. Significant tachycardia and hypertension [1] are associated with intubation. The elevation in arterial pressure typically starts within $5 \mathrm{~s}$ of laryngoscopy, peaks in 1-2 min, and returns to control levels within 5 min. Such hemodynamic changes can result in myocardial ischemia by increasing the myocardial oxygen requirement but seem to cause little harm to most patients. However, they are undesirable in patients with the coexisting cardiac disease.

Various drugs have been used to blunt this hemodynamic response such as $\beta$ blockers [2], $\alpha 2$ agonist [3], local anesthetics [4], and opioids [5]. Among the narcotics fentanyl, $6 \mu \mathrm{g} / \mathrm{kg}$ suppresses the hemodynamic response but risks prolonged respiratory depression. Among the $\beta$ blockers, the most commonly used is esmolol. Esmolol [6] is a selective $\beta 1$ receptor blocker with a very short duration of action. Esmolol because of its selective action decreases the cardiac output. This decrease in cardiac output increases the time to onset of action of rocuronium. Rocuronium [6] is an intermittently acting muscle relaxant. Its advantage is its quick onset of action which is comparable with succinylcholine. This advantage gets a little delayed due to the use of esmolol. Labetalol is a non-selective $\beta$ blocker [7] with additional $\alpha 1$ antagonistic property. It is primarily used for the treatment of hypertension. Labetalol due to its peripheral vasodilation property does not affect the cardiac output [8]. Labetalol has been shown to have an effect on blunting the hemodynamic response to tracheal intubation [9-11]. Thus, we hypothesized that labetalol while blunting the hemodynamic response to tracheal intubation will not lengthen the time to onset of action of rocuronium. Therefore, a prospective randomized, double-blind study was conducted on patients posted for mastoidectomy in the ear, nose, and throat (ENT) OT.

\section{METHODS}

After the study was approved by the Ethics Committee of the Institute of Medical Sciences (IMS) and SUM Hospital, we obtained a well-informed consent of 60 patients scheduled for mastoidectomy surgery. The study period lasted for 14 months starting from August 2015. The exclusion criteria were atherosclerosis, diabetes mellitus, asthma, hypertensive, any cardiac disorder, hemodynamically instability, hypersensitivity to the study drugs, Mallampatti Grade III/IV, and body mass index (BMI) more than 30 . The randomization was done using a computer generated random number table. Each consenting patient received a consecutive randomization number.

The patients were explained the procedure and the drugs used during the pre-anesthetic evaluation. Overnight anxiety was prevented by giving alprazolam $0.25 \mathrm{mg}$ tablet at bedtime along with one tablet of ranitidine $300 \mathrm{mg}$ to decrease gastric acid secretion. The study medication was administered in a double-blind fashion. An intravenous line was established.

All the patients received midazolam $2 \mathrm{mg}$ intravenous on arrival to the operation room. The study medication was prepared by a person not involved with the perioperative or post-operative care. The medication consisted of $0.25 \mathrm{mg} / \mathrm{kg}$ of labetalol diluted with $0.9 \%$ saline up to $10 \mathrm{ml}$ (Group B) and $0.5 \mathrm{mg} / \mathrm{kg}$ of esmolol diluted with $0.9 \%$ saline up to $10 \mathrm{ml}$ (Group A). Anesthesia was induced with propofol $2 \mathrm{mg} / \mathrm{kg}$ and fentanyl given at $2 \mathrm{mcg} / \mathrm{kg}$. Intubation was facilitated by rocuronium given at a dose of $1 \mathrm{mg} / \mathrm{kg}$ body weight. Intubation was done with an appropriately sized cuffed endotracheal tube. The duration to the onset of action of rocuronium was noted as the time for loss of all the twitch responses to a train of four stimulation. Patient taking more than $1 \mathrm{~min}$ from the time to laryngoscopy to intubation was eliminated from our study and not followed up. Patient lungs were mechanically ventilated with a mixture of oxygen:nitrous oxide at $1 \mathrm{~L}: 2 \mathrm{~L}$ along with isoflurane to maintain an EtCO2 of 4.5-5.0 kPa. After intubation, the monitoring was 
done after $1 \mathrm{~min}, 3 \mathrm{~min}, 5 \mathrm{~min}$, and $10 \mathrm{~min}$. Monitoring was continued every 15 min till the completion of the surgery.

After the completion of surgery, the patients were monitored every $2 \mathrm{~h}$ till $24 \mathrm{~h}$ of the administration of the study drug. Any episodes of bradycardia were treated with atropine, and episodes of hypotension were treated with fluid boluses. The adverse reactions noted in the patients were nausea, vomiting, and dizziness.

\section{Statistical analysis}

The patient's demographic data including the American Society of Anesthesiologists physical status classification, history of post-operative nausea and vomiting or motion sickness, and the incidence of side effects were analyzed using Fisher's exact test. The demographic data including age and BMI and clinical data including intergroup variations were analyzed by unpaired Student's t-test. The clinical data showing intragroup variation were analyzed using paired Student's t-test. The time to onset of action of rocuronium was analyzed by Mann-Whitney U-test. A p $<0.01$ was considered as statistically significant. The statistical analysis was performed using the Statistical Package for Social Sciences (SPSS $^{\text {тм }}$ ), Windows Versions 14.0, 15.0, and 16.0 (SPSS, Chicago, IL, USA).

\section{RESULTS}

The study was performed in the operating room of the ENT department in IMS and SUM Hospital, Bhubaneswar, India. 65 patients were screened and 60 patients were randomized and analyzed after surgery. The recruitment of the patients is depicted in the consort diagram (Fig. 1).

Distribution and duration of the surgical procedure were similar in the two groups as was the duration of surgery. The amount of propofol administered in the two group was similar.

The labetalol and esmolol group both showed a decline in heart rate and systolic blood pressure after drug administration. The hemodynamic changes were similar during the extubation period. The onset of action of rocuronium was decreased by $11 \%$ in the labetalol group, and this difference was statistically significant.

The adverse reactions were more in labetalol group (Fig. 2). Dizziness was seen in 11 patients taking labetalol, and it was statistically significant. Other side effects were more in labetalol group but not statistically significant.

\section{DISCUSSION}

The noxious response to tracheal intubation produces a hemodynamic response which is not desirable in patients suffering from cardiac disorders. Various drugs are used to attenuate this response. In our study, we found out that labetalol which is a non-specific $\beta$ blocker is as effective as esmolol in blunting of this response both during intubation as well as during extubation.

Rocuronium is an intermittent acting muscle relaxant. The unique ability of this drug compared to other intermittent acting muscle relaxant is its faster onset of action which is comparable with succinylcholine. The faster onset of action makes it suitable for use even in rapid sequence intubation $[12,13]$. The main drawback compared with succinylcholine is its much longer duration of action which restricts its use in a difficult airway scenario. A newly introduced drug called sugammadex [14,15] is a specific rocuronium antagonist, which reliably reverses the muscle relaxation produced by rocuronium given within minutes of rocuronium. This new drug now allows rocuronium to be reliable use in difficult airway scenario without worrying about the recovery of muscle power. Hence, rocuronium has the potential to replace succinylcholine [16], especially in those patients, it is not desirable to give succinylcholine which has an extensive list of its own side effects.

Esmolol has been very popular for attenuation of the hemodynamic response to tracheal intubation. It increases the onset of action of

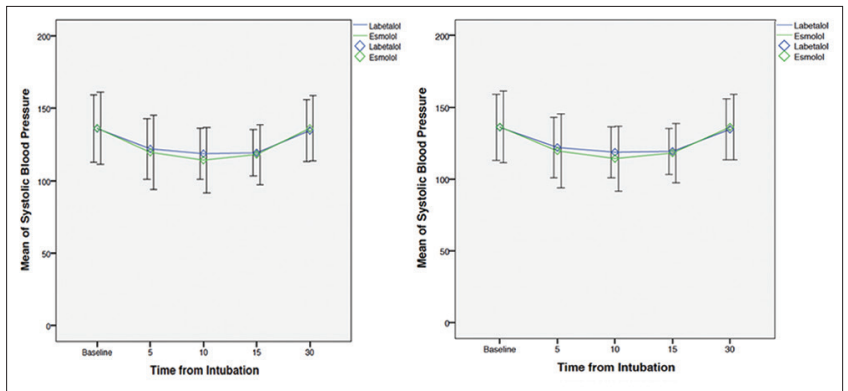

Fig. 1: Mean heart rate and mean blood pressure changes post intubation

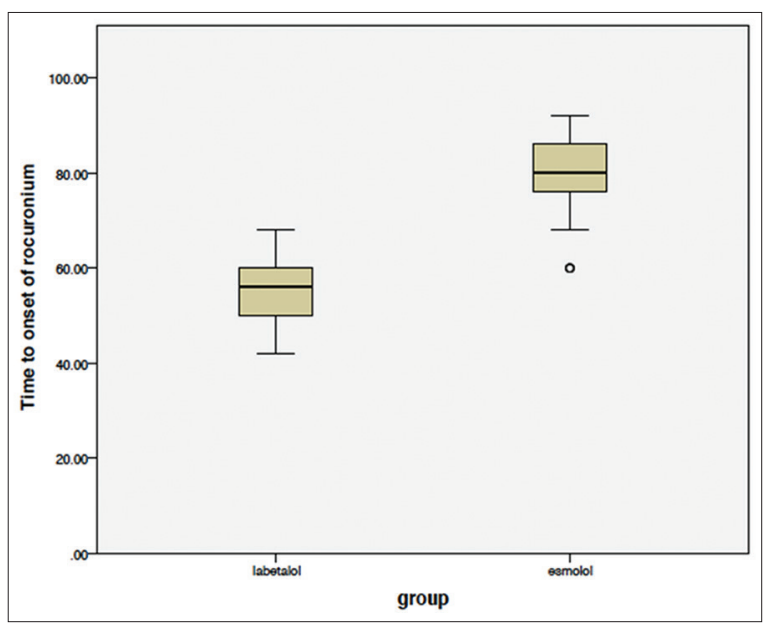

Fig. 2: Time to onset of acton of rocuronium

rocuronium by as much as $26 \%[17,18]$. It does this by predominantly decreasing the cardiac output. This may substantially increase the time to onset of action of rocuronium. This is not desirable in a rapid sequence intubation scenario where we want good relaxation and that too quickly. Lee et al. [19] have shown that nicardipine hastens the onset of action as compared to esmolol.

Labetalol a newer non-specific $\beta$ antagonist is mainly used for the treatment of hypertension and congestive cardiac failure. It has got peripheral vasodilating property because of its $\alpha 1$ antagonist property. In our study, labetalol reduced the time to onset of action of rocuronium, and this is mainly due to increased blood flow to the muscles. This helps to overcome the disadvantages of esmolol.

Labetalol also has a unique antioxidant property [20,21]. This may also help to decrease the stress response during surgery. The cost of labetalol is one-tenth that of esmolol. Thus, it has potential for use in difficult airway situations.

Further studies are required to establish the dosage and the role of labetalol in improving outcomes in difficult airway and head injury cases. The drawback of our study is the lack of any dose response. However, our main objective was to see whether labetalol is able to influence the time to onset of action of rocuronium or not. We can conclude that labetalol reduces the time to onset of action of rocuronium though further study is required to know the dose response of this drug for use as a premedication for anesthesia.

\section{REFERENCES}

1. Choyce A, Avidan MS, Harvey A, Patel C, Timberlake C, Sarang K, et al. The cardiovascular response to insertion of the intubating laryngeal mask airway. Anaesthesia 2002;57:330-3.

2. Feng $\mathrm{CK}$, Chan $\mathrm{KH}$, Liu KN, Or CH, Lee TY. A comparison of lidocaine, fentanyl, and esmolol for attenuation of cardiovascular 
response to laryngoscopy and tracheal intubation. Acta Anaesthesiol Sin 1996;34:61-7.

3. Kakkar A, Tyagi A, Nabi N, Sethi AK, Verma UC. Comparision of clonidine and dexmedetomidine for attenuation of laryngoscopy and intubation response - A randomized controlled trial. J Clin Anesth 2016;33:283-8.

4. Takita K, Morimoto Y, Kemmotsu O. Tracheal lidocaine attenuates the cardiovascular response to endotracheal intubation. Can J Anaesth 2001;48:732-6.

5. Striebel HW, Hölzl M, Rieger A, Brummer G. Endotracheal intubation with propofol and fentanyl. Anaesthesist 1995;44:809-17.

6. Wolman RL, Fiedler MA. Esmolol and beta-adrenergic blockade. AANA J 1991;59:541-8.

7. Orlowski JP, Vidt DG, Walker S, Haluska JF. The hemodynamic effects of intravenous labetalol for postoperative hypertension. Cleve Clin J Med 1989;56:29-34.

8. Feldman RL, Prida XE, Hill JA. Systemic and coronary hemodynamic effects of combined oral alpha- and beta-adrenergic blockade (labetalol) in normotensive patients with stable angina pectoris and positive exercise stress tests. Clin Cardiol 1988;11:383-8.

9. El-Shmaa NS, El-Baradey GF. The efficacy of labetalol vs dexmedetomidine for attenuation of hemodynamic stress response to laryngoscopy and endotracheal intubation. J Clin Anesth 2016;31:267-73.

10. Singh SP, Quadir A, Malhotra P. Comparison of esmolol and labetalol, in low doses, for attenuation of sympathomimetic response to laryngoscopy and intubation. Saudi J Anaesth 2010;4:163-8.

11. Meftahuzzaman SM, Islam MM, Ireen ST, Islam MR, Kabir H, Rashid $\mathrm{H}$, et al. Comparison of efficacy of labetalol and fentanyl for attenuating reflex responses to laryngoscopy and intubation. Mymensingh Med J 2014;23:242-8.
12. Tran DT, Newton EK, Mount VA, Lee JS, Wells GA, Perry JJ, et al. Rocuronium versus succinylcholine for rapid sequence induction intubation. Cochrane Database Syst Rev 2015;???:CD002788.

13. Lysakowski C, Suppan L, Czarnetzki C, Tassonyi E, Tramèr MR. Impact of the intubation model on the efficacy of rocuronium during rapid sequence intubation: Systematic review of randomized trials. Acta Anaesthesiol Scand 2007;51:848-57.

14. Sparr HJ, Booij LH, Fuchs-Buder T. Sugammadex. New pharmacological concept for antagonizing rocuronium and vecuronium. Anaesthesist 2009;58:66-80.

15. Caldwell JE, Miller RD. Clinical implications of sugammadex. Anaesthesia 2009;64 Suppl 1:66-72.

16. Di Filippo A, Gonnelli C. Rapid sequence intubation: A review of recent evidences. Rev Recent Clin Trials 2009;4:175-8.

17. Ezri T, Szmuk P, Warters RD, Gebhard RE, Pivalizza EG, Katz J, et al. Changes in onset time of rocuronium in patients pretreated with ephedrine and esmolol-the role of cardiac output. Acta Anaesthesiol Scand 2003;47:1067-72

18. Szmuk P, Ezri T, Chelly JE, Katz J. The onset time of rocuronium is slowed by esmolol and accelerated by ephedrine. Anesth Analg 2000;90:1217-9.

19. Lee JH, Kim Y, Lee KH, Rim SK, Lee JY, Lee C, et al. The effects of nicardipine or esmolol on the onset time of rocuronium and intubation conditions during rapid sequence induction: A randomized doubleblind trial. J Anesth 2015;29:403-8.

20. Kouoh F, Gressier B, Dine T, Luyckx M, Brunet C, Ballester L, et al. In vitro and ex vivo antioxidant activities of labetalol on rabbit neutrophil respiratory burst. Adv Ther 2004;21:178-85.

21. Jhansi C, Harshini M, Sandeep K, Rao PC, Lakshmi CH. Comparision of efficacyand safety of oral labetalol and Nifedipine in preeclampsia: A prospective observational study. Int J Pharm Pharm Sci 2015;7:277-80. 